\title{
Bacillus Calmette-Guérin induces the expression of peroxisome proliferator-activated receptor gamma in bladder cancer cells
}

\author{
CATALINA LODILLINSKY* ${ }^{*}$ MARÍA SOL UMEREZ*, MARÍA ADELA JASNIS, \\ ALBERTO CASABÉ, EDUARDO SANDES and ANA MARÍA EIJÁN \\ Research Area from Institute of Oncology Angel H. Roffo, University of Buenos Aires, \\ Av. San Martín 5481, CP1417 DTB, Buenos Aires, Argentina
}

Received September 6, 2005; Accepted October 26, 2005

\begin{abstract}
Bacillus Calmette-Guérin (BCG) is considered to be one of the most effective treatments for superficial and in situ bladder cancer. The exact mechanism of the antitumor activity of BCG is not completely understood. Peroxisome proliferatoractivated receptor gamma (PPAR $\gamma)$ is a member of the nuclear receptor superfamily of ligand-activated transcription factors that is involved in cell growth and differentiation as well as inflammatory processes. PPAR $\gamma$ is expressed in normal urothelium and a lack of expression was associated with bladder cancer progression. We analyzed whether PPAR $\gamma$ is involved in the inhibition of bladder cancer cell survival by BCG. PPAR $\gamma$ expression in murine MB49 and human T24 bladder cancer cells was evaluated employing immunofluorescence and inmunohistochemistry techniques. In vitro cell viability and nitric oxide (NO) production was evaluated by using MTS and Griess reagent respectively. Our results show that BCG induced the cytoplasmatic expression of PPAR $\gamma$ in bladder tumor cells in vitro and in vivo. BADGE, antagonist of this receptor, abrogated in vitro BCG-mediated cell cytotoxicity. Natural agonist 15 -deoxy- $\Delta 12,14$ prostaglandin $\mathrm{J} 2$ (15-d-PGJ2) but not rosiglitazona (RO), a synthetic agonist, induced in vitro inhibition of cell viability of both cancer cell lines and the effect was partially reversed by BADGE. We also determined whether the activation of PPAR $\gamma$ could inhibit NO production, which is considered a survival factor for bladder tumor cells. Both 15-d-PGJ2 and RO significantly inhibited the NO production in T24 and MB49 cells by PPAR $\gamma$ independent pathway since it was not antagonized by BADGE.
\end{abstract}

Correspondence to: Dr Ana María Eiján, Área Investigación, Instituto de Oncología Angel H. Roffo, Av. San Martín 5481, CP1417 DTB, Buenos Aires, Argentina

E-mail: anamariaeijan@fibertel.com.ar

\section{${ }^{*}$ Contributed equally}

Key words: bladder cancer, Bacillus Calmette-Guérin, peroxisome proliferator-activated receptor gamma, nitric oxide
Thus, our results show that BCG induces functional PPAR $\gamma$ in bladder tumor cells in vivo and in vitro, being these receptors intrinsically involved in the antitumor activity of BCG.

\section{Introduction}

Intravesical administration of Bacillus Calmette-Guérin (BCG) plays a major role in the treatment and prophylaxis of recurrent superficial and in situ bladder carcinoma (1).

The exact mechanism of the antitumor activity of BCG is not completely understood but it seems to involve direct effects on tumor cells and others mediated by immune cells. It is well known that BCG evokes an early local and nonspecific immune cell reaction including increase in cytokine production and finally Th1 cell-regulated cytotoxicity $(2,3)$. Previously, we have demonstrated that BCG induced in vitro bladder tumor cell death by a mechanism independent of concomitant production of nitric oxide (4).

PPAR $\gamma$ is a member of the nuclear receptor superfamily of ligand-activated transcription factors and functions as a regulator of adipocyte differentiation and lipid metabolism (5). PPAR $\gamma$ is expressed at high levels in white adipose tissue and is also highly expressed in many other specialized cells, such as macrophages (6), T cells (7), smooth muscle cells of the arterial wall (8) and epithelial cells, including rodent and human urothelial cells $(9,10)$. Receptor activation has also been implicated in inflammation and tumorigenesis. PPAR $\gamma$ is up-regulated in some malignant tissue, and its ligands induce terminal differentiation and/or growth inhibition of human breast, colon, prostate, gastric and lung cancer cells $(11,12)$. PPAR $\gamma$ can be activated by a number of ligands, either natural such as 15 -deoxy- $\Delta^{12,14}$-prostaglandin $\mathrm{J}_{2}$ (15-d-PGJ2) (13) or synthetic such as antidiabetic thiazolidinediones (TZD) (14). Activation of PPAR $\gamma$ by troglitazone, a TZD, induces differentiation and reversal of malignancy in different tumors $(15,16)$.

The function of PPAR $\gamma$ on urothelium is unknown and the finding that it is expressed in urothelial tumor cells raised questions about the role of PPAR $\gamma$ and its ligands in bladder cancer. It has been described that activation of PPAR $\gamma$ in bladder cancer cell lines in vitro induced growth inhibition and even cell death $(10,17)$. Although there is a discrepancy 
about the significance of PPAR $\gamma$ expression in bladder tumors $(10,18,19)$, the consensus is that the presence of PPAR $\gamma$ in bladder tumor cells should be considered an indicator of good prognosis or, conversely, the lack of expression of PPAR $\gamma$ can be associated with tumor progression. Thus, one might assume that reexpression induction of PPAR $\gamma$ could induce regression of bladder tumors.

In order to investigate whether PPAR $\gamma$ are linked to BCGinduced bladder tumor cell death, we first determined the PPAR $\gamma$ expression in tumor cells followed by an evaluation of their participation in BCG-mediated tumor cell cytotoxicity. Our results demonstrate that BCG induced PPAR $\gamma$ expression in bladder tumor cells in vitro and in vivo. Furthermore, a PPAR $\gamma$ antagonist abrogated in vitro BCG-mediated cell cytotoxicity. In summary, we can suggest that an efficient BCG therapy involves induction of PPAR $\gamma$ in bladder cancer cells.

\section{Materials and methods}

Tumor cell lines. Human T24 (obtained from ATCC, Bethesda, MD) and murine MB49 (obtained from Dr E.C. Lattime, Thomas Jefferson University, Philadelphia, PA) bladder cancer cell lines were cultured in MEM (41500, Gibco BRL) supplemented with $3 \mathrm{mM}$ L-glutamine, $80 \mu \mathrm{g} / \mathrm{ml}$ gentamycin and $8 \%$ fetal calf serum (FCS).

$B C G$. Living organisms of an attenuated strain of Mycobacterium bovis [Pasteur $1172 \mathrm{P} 2$ strain, containing $3 \times 10^{6}$ colony forming units (CFU) per $\mathrm{mg}$ ] were obtained from Instituto Nacional de Producción de Biológicos ANLIS C.G. Malbrán, Buenos Aires, Argentina.

Immunofluorescence of PPAR $\gamma$ in bladder cancer cells. T24 or MB49 cells ( $2 \times 10^{5} /$ wells) were cultured for $48 \mathrm{~h}$ on cover slides in 6-well culture dishes, with or without $2 \times 10^{6} \mathrm{CFU}$ of $\mathrm{BCG} / \mathrm{ml}$. Slides were then gently washed with cool saline buffer and processed for immunofluorescence. Briefly, slides were first permeabilized and unspecific blocking was performed using Tween-20 1\% plus casein 10\% in PBS for 90 min at room temperature. Rabbit polyclonal antibody anti-PPAR $\gamma$ (H-100, Santa Cruz Biotechnology, Inc) diluted 1:50 was used overnight. Goat anti-rabbit IgG-fluorescein conjugated, diluted 1:50, was used as secondary antibody (Chemicon International, Inc) for $60 \mathrm{~min}$ and counterstained with ethidium bromide. Slides were observed using a fluorescence Nikon Eclipse E400 microscope and photographs were obtained using a digital camera, Nikon Cool PIX 995, at a magnification x200.

In vivo treatment of MB49 tumor bearing mice. To assay if BCG was able to induce PPAR $\gamma$ expression in vivo, MB49 cells $\left(4 \times 10^{5} / 0.1 \mathrm{ml}\right)$ were injected subcutaneously into the flanks of syngeneic C57BL/6J mice as previously described (4). BCG $\left(2 \times 10^{6} \mathrm{CFU} / \mathrm{ml}\right)$ was injected intratumorally once a week starting $24 \mathrm{~h}$ after tumor cell inoculation. After 14 days, mice were necropsied and tumors were fixed in $10 \%$ neutral buffer formalin and processed for routine hematoxilin-eosin and immunohistochemistry.

Mice (approximately 8 weeks old) were obtained from our Animal Care Division. Animal care was provided in accordance with the procedure outlined in the Guide for the Care and Use of Laboratory Animals (NIH publications 1986).

Inmunohistochemistry. Paraffin-embedded sections from MB49 bladder tumors ( $\mathrm{n}=6 ; 3$ controls and 3 from BCG-treated mice), were used to analyze the PPAR $\gamma$ expression. Inmunohistochemical staining was performed using an avidin-biotinyl peroxidase complex as previously described (20) with the unique modification that the first antibody was PPAR $\gamma$ specific (H-100, Santa Cruz Biotechnology, Inc).

Assay of in vitro tumor cell survival and nitric oxide production. Tumor cell lines $\left(1 \times 10^{4}\right.$ cells/200 $\left.\mu 1\right)$ were cultured in 96-well plates (Greiner Labortechnik $\mathrm{GmbH}$, Frickenhausen, Germany) at $37^{\circ} \mathrm{C}$ in a $5 \% \mathrm{CO}_{2}$ humidified atmosphere. After $24 \mathrm{~h}$ incubation, different concentrations $(0.1,1,10$ and $50 \mu \mathrm{M})$ of natural (15-d-PGJ2; Cayman Chemical, USA) or synthetic (rosiglitazona, RO; ELEA, Buenos Aires, Argentina) PPAR $\gamma$ agonists with or without BCG $\left(2 \times 10^{6} \mathrm{CFU} / \mathrm{ml}\right)$ were added. The PPAR $\gamma$ antagonist, bisphenol A diglycidyl ether (BADGE; FLUKA Chemical $\mathrm{GmbH}$, Buchs, Switzerland), was also used. Cells were cultured for an additional $48 \mathrm{~h}$. The cytostatic/cytotoxic effect of BCG was assessed using a non-radioactive cell titer (Cell Titer 96 Aqueous, MTS; Promega). Nitric oxide (NO) production in tumor cell supernatants was determined by using Griess reagent (21). Different concentrations of sodium nitrite were used to construct a standard curve. Results of NO production are expressed as nitrite $\mu \mathrm{M}$. Absorbance was measured at 492 or $550 \mathrm{~nm}$ for MTS or NO determination, respectively, using an ELISA reader (Multiskan Ascent, Labsystem).

Statistical analysis. Results are expressed as mean \pm SD of almost six replicates per group. Significance of differences was calculated by one-way ANOVA, by using Graph Pad InStat statistical package (version 3.01). Bonferroni contrast was used to compare the in vitro assays. All experiments were repeated at least 3 times with similar results.

\section{Results}

$B C G$ induced PPAR $\gamma$ expression in bladder cancer cells in vitro and in vivo. As PPAR $\gamma$ has been associated with the inhibition of tumor cell growth, we studied whether BCG activity on bladder cancer cells was associated with the induction of PPAR $\gamma$ expression. Neither MB49 nor T24 cell lines expressed PPAR $\gamma$ in basal conditions as determined by immunofluorescence. However, the in vitro addition of BCG to cultured cells induced cytoplasmatic PPAR $\gamma$ expression in both cell lines (Fig. 1A-D). BADGE abrogated in vitro BCGmediated cell cytotoxicity (Fig. 2) suggesting that this receptors are involved death of tumor cells.

Immunohistochemical studies showed that in MB49 tumors, growing in the flank of $\mathrm{C} 57 \mathrm{Bl} / \mathrm{J} 6$ mice. BCG treatment also induced PPAR $\gamma$ expression on tumor cells, while control tumors were negative (Fig. $1 \mathrm{~F}$ and $\mathrm{E}$ respectively).

Effect of PPAR $\gamma$ agonist on tumor cell survival and nitric oxide production. 15-d-PGJ2, the major natural agonist of 

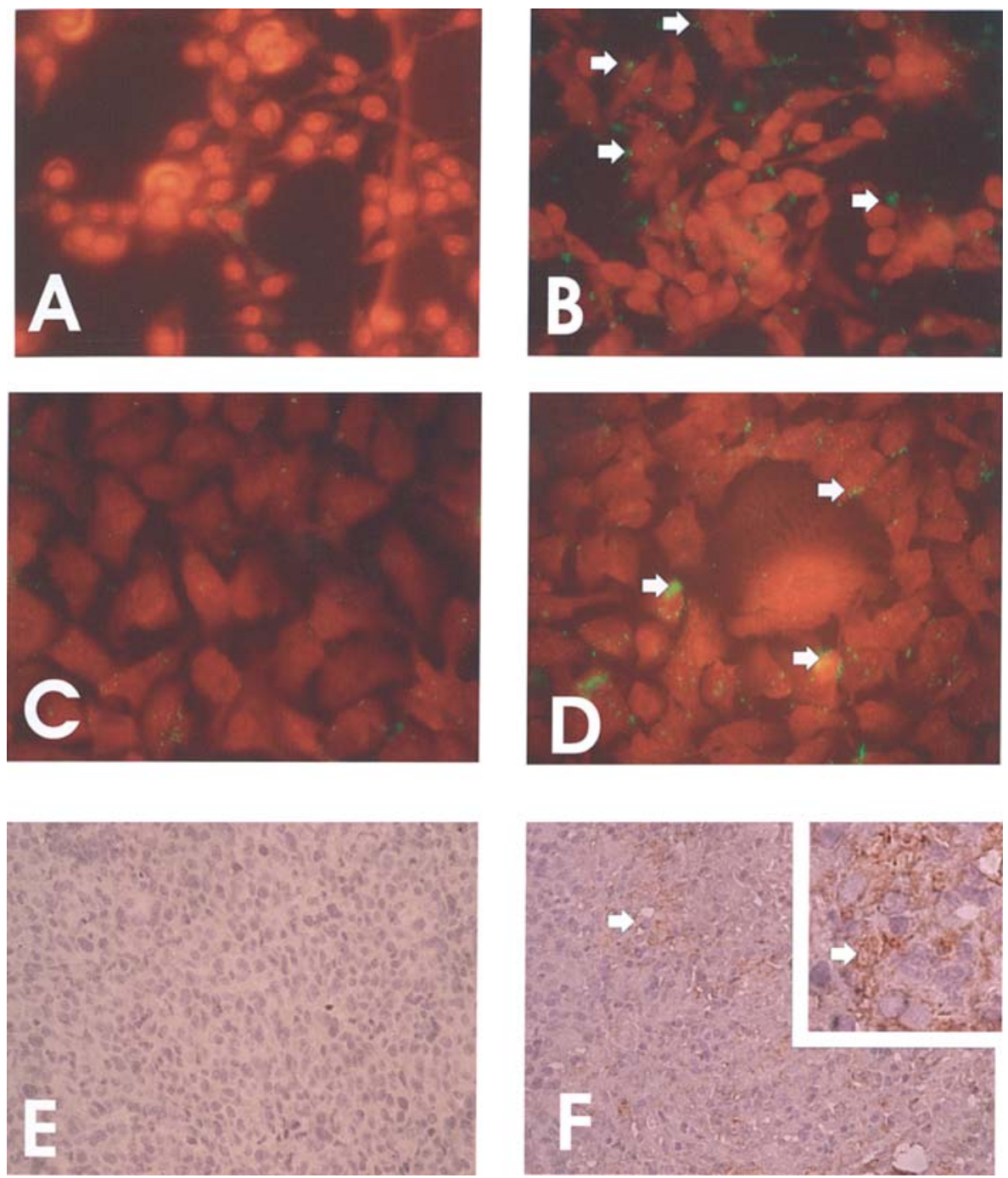

Figure 1. Representative immunostaining for PPAR $\gamma$ in bladder cancer cell lines in vitro and in vivo. Negligible PPAR $\gamma$ expression was found in MB49 (A) and T24 (C) cells in vitro and in MB49 cells growing s.c. in C57BL/J6 mice (E). Upon BCG treatment, immunoreactive PPAR $\gamma$ was detected either in vitro in MB49 cells (B) and T24 cells (D) or in vivo (F). Photograph magnification, $\mathrm{x} 100$; insert, $\mathrm{x} 400$.

PPAR $\gamma$, induced in vitro inhibition of cell viability of both murine and human bladder cancer cell lines, with human T24 being more sensitive ( $40 \%$ inhibition at $0.1 \mu \mathrm{M} \mathrm{15-d-PGJ2}$ and $60 \%$ at $10 \mu \mathrm{M}$ ) than murine MB49 cells (approximately $20 \%$ inhibition at all concentrations) (Fig. 3). It is noteworthy that the 15-d-PGJ2 inhibitory effect was only detected when cells were cocultured in the presence but not in the absence of BCG. We also demonstrated that the inhibiton of cell viability by 15 -d-PGJ 2 was PPAR $\gamma$-dependent since it was partially reversed by BADGE $(40 \mu \mathrm{M})$. By the contrary, RO, alone or in combination with BADGE, did not affect the cell viability of either cell line (Fig. 3).

As PPAR $\gamma$ are negative regulators of inflammation and, thus, of NO production, and as we have previously suggested that NO could be a survival factor for bladder tumor cells (4), we evaluated whether $15-\mathrm{d}-\mathrm{PGJ} 2$ and RO could inhibit NO production upon BCG treatment. Our results show that both ligands significantly inhibited NO production in T24 and MB49 cells. In T24 cells, the inhibition by RO was dosedependent (10\% inhibition at $0.1 \mu \mathrm{M}$ and $28 \%$ at $1 \mu \mathrm{M}$, reaching a plateau of $35 \%$ inhibition at $10 \mu \mathrm{M}$ ). The inhibitory effect of 15-d-PGJ2 was less evident (approximately 25\% at

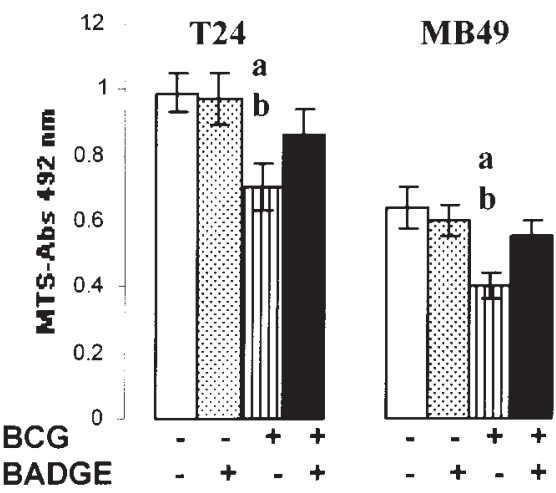

Figure 2. Subconfluent monolayers of bladder cancer cell lines growing in 96-well plates were incubated for $48 \mathrm{~h}$ with or without viable BCG, with or without BADGE (40 mM). Cell viability was evaluated by MTS, and referred to as fold of control. a, $\mathrm{p}<0.001$ between cells with or without $\mathrm{BCG}$; and $\mathrm{b}, \mathrm{p}<0.01$ between cells with BCG and BCG + BADGE.

all doses). In this case, the effect of both ligands on NO production was PPAR $\gamma$-independent since it was not antagonized by BADGE. MB49 cells were more sensitive to NO 

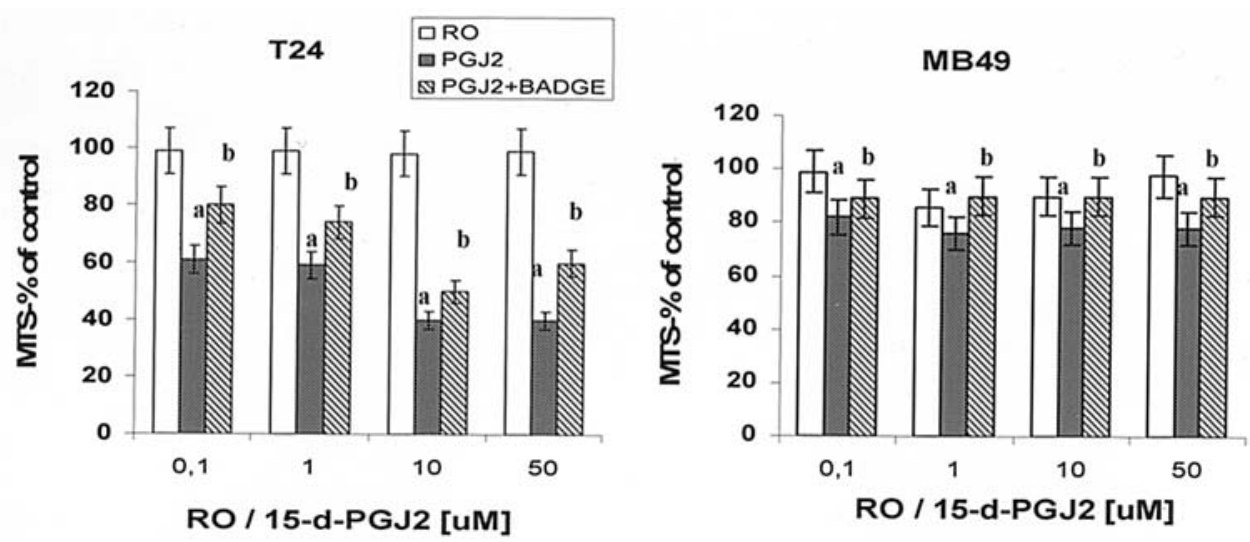

Figure 3. Subconfluent monolayers of bladder cancer cell lines growing in 96-well plates were incubated for $48 \mathrm{~h}$ with BCG plus RO or 15-d-PGJ2, with or without BADGE (40 mM). Cell viability was evaluated by MTS, and referred to as fold of control. 15-d-PGJ2 significantly inhibited the cell viability (a, $\mathrm{p}<0.001)$ and this effect was reversed by BADGE $(\mathrm{b}, \mathrm{p}<0.01)$.
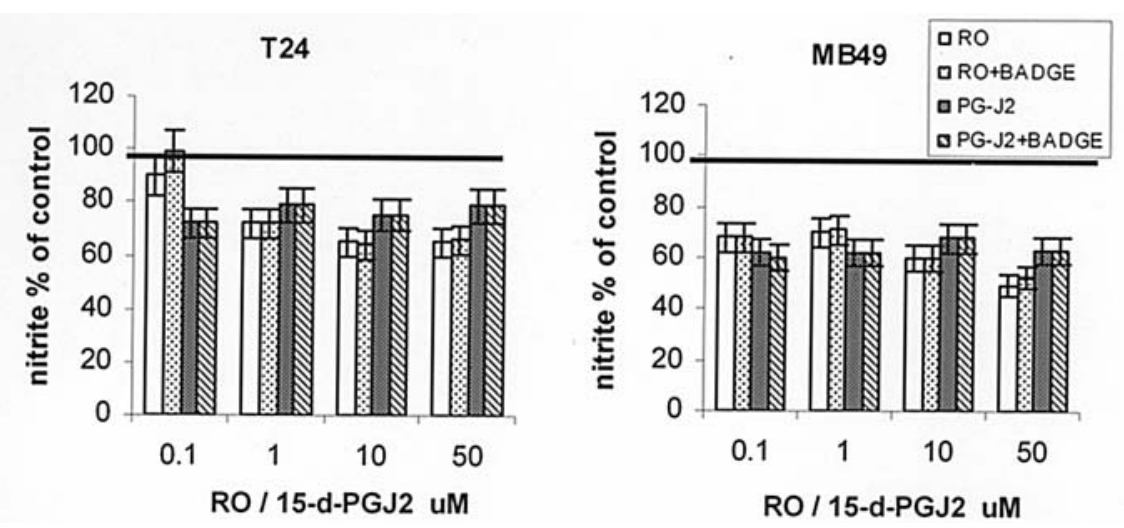

Figure 4. NO production by tumor cell lines was evaluated in the supernatants by using Griess reagent. Both RO and 15-d-PGJ2 at all concentrations inhibited the NO production induced by BCG $(\mathrm{p}<0.01)$ and this was not reversed by BADGE.

inhibition by RO and PGJ2 (30-40\% inhibition) than T24 cells (Fig. 4). Our results suggest that inhibition of NO upon BCG treatment appears to be PPAR $\gamma$-independent.

\section{Discussion}

Intravesical administration of BCG is used for therapy and prophylaxis of recurrent superficial and in situ bladder carcinoma (1). The mode of action against bladder carcinoma remains unclear, but it is well known that BCG evokes an early local and non-specific immune cell reaction (2,3). A direct effect on tumor cells was also observed although this pathway has been less explored. Results from our laboratory have shown that BCG induced in vitro an NO-independent inhibition of bladder cancer cell growth. Furthermore, the in vivo inhibition of NO improved BCG therapy (4).

The present experiments were designed to better understand the mechanisms exerted by BCG on bladder tumor cells.

Several reports have demonstrated that PPAR $\gamma$ are involved in cancer cell growth inhibition $(10-12,15,16)$. It was described that transitional bladder epithelia expresses PPAR $\gamma$ and its lack of expression in bladder cancer is associated with a bad prognosis $(10,18)$. Thus, we studied whether PPAR $\gamma$ are involved in BCG-induced bladder tumor cell death. We observed that PPAR $\gamma$ expression was weak or absent in MB49 and T24 cells and that the addition of BCG induced its cytoplasmatic expression (Fig. 1). When different PPAR $\gamma$ agonists were used in vitro inhibition of cell viability was only detected with 15-d-PGJ2 and not with RO. The tumor cell lines were not equally sensitive to 15 -d-PGJ2, murine being more resistant than human cells. It is noteworthy that the effect of 15-d-PGJ2 was only detected in the presence of BCG. According to these results, we can assume that BCG has the ability to induce functional PPAR $\gamma$ which can respond only to the endogenous ligand.

PPAR $\gamma$ ligands can also exert a PPAR $\gamma$-independent effect (16). In our system, we demonstrated that inhibition of cell viability by 15 -d-PGJ2 was PPAR $\gamma$-dependent since BADGE, a specific PPAR $\gamma$ antagonist, reversed the prostanoid effect (Fig. 3). BADGE also directly reversed BCG-mediated cell death (Fig. 2), confirming that PPAR $\gamma$ are involved in BCG cytotoxic activity. Thus, we can assume that functional PPAR $\gamma$ induced by BCG are involved in any of the pathways that lead to tumor death. It can be hypothesized that the endogenous concentration of 15-d-PGJ2 after BCG therapy could provide a better response to this biotherapy.

Since it is known that PPAR $\gamma$ down-regulate iNOS expression and function (22) and BCG response is associated with NO production, we assayed whether 15-d-PGJ2 and RO modulated the NO production concomitantly with BCG. 
A combined treatment of BCG with either RO or 15-dPGJ2 inhibited the NO production. This inhibitory activity was PPAR $\gamma$-independent since it was not reversed by BADGE. No modifications of NO levels were detected in the absence of BCG. Although a PPAR $\gamma$-independent mechanism has been previously described for synthetic agonist concentrations of $>10 \mu \mathrm{M}$ (23), we detected the inhibition of NO production from $0.1 \mu \mathrm{M}$ of $\mathrm{RO}$ or $15-\mathrm{d}-\mathrm{PGJ} 2$.

It is of interest that, in bladder cancer cells, PPAR $\gamma$ agonists may function via either PPAR-dependent or -independent pathways, being cell death-dependent, while the inhibition of NO production seems to act via a PPAR $\gamma$-independent pathway.

Our previous results indicate that expression of inducible NO synthase (iNOS) is a bad prognosis factor for bladder cancer patients (20). Thus, we can hypothesize that RO or 15-d-PGJ2, by inhibiting NO production, might be a valuable therapeutic tool for patients with tumors expressing iNOS. However, this approach needs further research as both TZD and $15-\mathrm{d}-\mathrm{PGJ} 2$ are immune suppressors $(7,22,24)$ and their use may abrogate the immune response to BCG.

In summary, our results show that BCG induces functional PPAR $\gamma$ in bladder tumor cells in vivo and in vitro and that these receptors are intrinsically involved in the antitumor activity of BCG. Levels of endogenous agonists, such as 15d-PGJ2, could predict whether BCG immunotherapy would be successful or not.

\section{Acknowledgements}

We thank Dr Claudia Arguelles and Alicia Trovero from Instituto Nacional de Producción de Biológicos Dr Carlos G. Malbrán, Buenos Aires, Argentina for providing BCG. Catalina Lodillinsky is a fellow of Universidad de Buenos Aires. Ana María Eiján is a member of Consejo Nacional de Investigaciones Científicas y Técnicas (CONICET). This work was supported by grants, CONICET-PIP 02032 and UBACYT M015.

\section{References}

1. Lamm DL, Van Der Meijden ADPM, Moraels A, Brosman SA, Catalona WJ, Herr HW, Soloway MS, Steg A and Debruyne FMJ: Incidence and treatment of complications of bacillus CalmetteGuérin intravesical therapy in superficial bladder cancer. J Urol 147: 568-571, 1992.

2. Suttmann H, Jacobsen M, Reiss K, Jocham D, Bohle A and Brandau S: Mechanisms of bacillus Clamette Guérin mediated natural killer cell activation. J Urol 172: 1490-1495, 2004.

3. Kaasinen ES, Harju LM, Alfthan OS and Timonen TT: Nonspecific, rapidly generated cytotoxicity in lymphocytes induced by BCG in vitro: no evidence of enhancing effect from preceding interaction between BCG and transitional cell line cells. J Urol 163: 317-322, 2000.

4. Alvarez V, Lodillinsky C, Umerez S, Sandes E and Eiján AM: Inhibition of Bacillus Calmette Guérin-induced nitric oxide in bladder tumor cells may improve BCG treatment. Int J Mol Med 16: 565-571, 2005.

5. Braissant O, Foufelle F, Scotto C, Dauca MA and Wahli W: Differential expression of peroxisome proliferator-activated receptors (PPARs) tissue distribution of PPAR-alfa, -beta and gamma in adult rats. Endocrinology 137: 354-366, 1996.

6. Tontonoz P, Nagy L, Alvarez JG, Thomazy VA and Evans RM: PPARg promotes monocyte/macrophage differentiation and uptake of ocideized LDL. Cell 93: 241-252, 1998.
7. Clark RB, Bioshop-Bailey D, Estrada-Hernandez T, Hla T, Puddington L and Padula SJ: The nuclear receptor PPAR $\gamma$ and immunoregulation: PPAR $\gamma$ mediates inhibition of helper $\mathrm{T}$ cell responses. J Immunol 164: 1364-1371, 2000.

8. Law RE, Goetze S, Xi XP, Jackson S, Kawano Y, Demer L, Fishbein MC, Meehan WP and Hsueh WA: Expression and function of PPAR $\gamma$ in rat and human vascular smooth muscle cells. Circulation 101: 1311-1318, 2000.

9. Guan Y, Zhang Y, Davis L and Breyer MD: Expression of peroxisome proliferator-activated receptor in urinary tract of rabbits and humans. Am J Physiol 273: F1013-F1022, 1997.

10. Nakashiro K, Hayahi Y, Kita A, Tamatani T, Chlenski A, Usuda N, Hattori K, Reddy JK and Oyasu R: Role of peroxisome proliferator-activated receptor $\gamma$ and its ligands in non-neoplastic and neoplastic human urothelial cells. Am J Path 159: 591-597, 2001.

11. Chang TH and Szabo E: Ligands for peroxisome proliferatoractivated receptor gamma and retinoic acid receptor inhibit growth and induce apoptosis of human breast cancer cells in vitro and in BNX mice. Cancer Res 60: 1129-1138, 2000.

12. Schaefer KL, Wada K, Takahashi H, Matsuhashi N, Ohnishi S, Wolfe MM, Turner JR, Nakajima A, Borkan SC and Saubermann LJ: Peroxisome proliferator-activated receptor $\gamma$ inhibition prevents adhesion to the extracellular matrix and induces anoikis in hepatocellular carcinoma cells. Cancer Res 65: 2251-2259, 2005.

13. Forman BM, Tontonoz P, Chen J, Brun RP, Spiegelman BM and Evans RM: 15-Deoxy-delta 12,14-prostaglandin J2 is a ligand for the adipocyte determination factor PPAR gamma. Cell 83: 803-812, 1995.

14. Lehmann JM, Moore LB, Smith-Oliver TA, Wilkinson WO, Willson TM and Kliewer SA: An antidiabetic thaiazolidinediones is a high affinity ligand for peroxisome proliferator-activated receptor gamma (PPAR $\gamma)$. J Biol Chem 270: 12953-12956, 1995.

15. Inoue K, Kawahito Y, Tsubouchi Y, Kohno M, Yoshimura R, Yoshikawa T and Sano H: Expression of peroxisome proliferatoractivated receptor gamma in renal cell carcinoma and growth inhibition by its agonists. Biochem Biophys Res Commun 287: 727-732, 2001.

16. Shiau CW, Yang CC, Kulp SK, Chen KF, Chen CS, Huang JW and Chen CS: Thiazolidenediones mediate apoptosis in prostate cancer cells in part through inhibition of Bcl-xL/Bcl-2 functions independently of PPAR $\gamma$. Cancer Res 65: 1561-1569, 2005.

17. Guan YF, Zhang YH, Breyer RM, Davis L and Breyer MD: Expression of peroxisome proliferator-activated receptor gamma (PPAR $\gamma$ ) in human transitional bladder cancer and its role in inducing cell death. Neoplasia 1: 330-339, 1999.

18. Possati L, Rocchetti R, Talevi S, Beatrici V, Margiotta C, Ferrante L, Calza R, Sagrini D and Ferri A: The role of peroxisome proliferator-activated receptor gamma in bladder cancer in relation to angiogenesis and progression. Gen Pharmacol 35: 269-275, 2002.

19. Yoshimura R, Matsuyama M, Segawa Y, Hase T, Mitsuhashi M, Tsuchida K, Wada S, Kawahito Y, Sano H and Nakatani T: Expression of peroxisome proliferator-activated receptors (PPARs) in human urinary bladder carcinoma and growth inhibition by its agonists. Int J Cancer 104: 597-602, 2003.

20. Sandes EO, Faletti AG, Riveros MD, Vidal MC, Gimenez L, Casabé AR and Eiján AM: Expression of inducible nitric oxide synthase in tumoral and non-tumoral epithelia from bladder cancer patients. Nitric Oxide 12: 39-45, 2005.

21. Granger DL, Hidds JB, Perfect JR and Durack DT: Metabolic fate of L-arginine inhalation to microbiostatec capability of murine macrophages. J Clin Invest 85: 264-267, 1990.

22. Ricote M, Li AC, Willson TM, Kelly CJ and Glass CK: The peroxisome proliferators-gamma is a negative regulator of macrophage activation. Nature 391: 79-82, 1998.

23. Crosby MB, Svenson JL, Zhang J, Nicol CJ, Gonzalez FJ and Gilkeson GS: Peroxisome proliferation-activated receptor (PPAR) gamma is not necessary for synthetic PPARgamma agonist inhibition of inducible nitric-oxide synthase and nitric oxide. J Phamacol Exp Ther 312: 69-76, 2005.

24. Asuma Y, Shinohara M, Pao-Li Wang and Ohura K: 15-deoxydelta $^{12,14}$-prostaglandin $\mathrm{J} 2$ is a negative regulator of macrophage functions. Int J Immunopharmacol 12: 2101-2108, 2001. 